\title{
Maritime Archaeology and Capacity Development in the Global South
}

\author{
Lucy Blue $^{1} \cdot$ Colin Breen ${ }^{2}$ (D) \\ Published online: 4 November 2019 \\ (C) The Author(s) 2019
}

\begin{abstract}
The Honor Frost Foundation sponsored a session, 'Maritime Archaeology, Capacity Building and Training in the Developing World' at the Sixth International Congress on Underwater Archaeology (IKUWA VI) held in Freemantle, Australia, in November 2016, dedicated to capacity development in the context of maritime archaeology. The papers presented in this special issue of this journal represent an attempt to understand different approaches to capacity building and development within the sphere of maritime cultural heritage. This paper, by way of an introduction to the subject, and this special issue, aims to explore the nature of capacity building and development in relation to maritime cultural heritage.
\end{abstract}

Keywords Maritime archaeology · Capacity · Development · Global South · Honor Frost Foundation

\section{Introduction}

In 2011 the Honor Frost Foundation was established in memory of a remarkable pioneer in the field of maritime archaeology. It was set up to promote the advancement and research of maritime archaeology primarily in the eastern Mediterranean, with a focus on Syria, Lebanon and Cyprus. While the level of funding available to the Foundation represented a significant opportunity for the development of the subject, it also presented a set of very real practical and theoretical challenges. The political complexity of the region and continuing conflict posed one set of challenges, but a parallel set of heritage practice related challenges also presented themselves. In particular, both the Foundation's board of trustees and archaeological advisors were tasked with developing a sustainable legacy for maritime

Colin Breen

CP.Breen@ulster.ac.uk

Lucy Blue

lkb@soton.ac.uk

1 Centre for Maritime Archaeology, University of Southampton, University Road, Southampton SO17 1BJ, UK

2 School of Geography and Environmental Sciences, Ulster University, Coleraine BT52 1SA, Northern Ireland, UK 
archaeology across the region. But what would that legacy actually look like? Nothing like this had ever presented itself before in terms of maritime heritage research. The region had extremely limited capacity for development in this field, and the fund was effectively starting with a blank canvass in terms of subject development. Of particular concern to the Foundation's advisors was the general absence of capacity across the countries. Understandably, this has subsequently become a particular focus of the Foundation's work.

The papers presented in this special issue represent an attempt to understand different approaches to capacity development within the sphere of maritime cultural heritage. The majority of the papers were presented at a special session at IKUWA VI (Sixth International Congress on Underwater Archaeology) held in Freemantle, Australia, in November 2016, sponsored by the Honor Frost Foundation. That session was dedicated to capacity building in the context of maritime archaeology, but also by way of introduction to the subject matter more broadly. The session papers, and a number of subsequent invited contributions, represent a gap and therefore a need to supplement the current literature, with respect to a consideration of the issues relating to maritime archaeology and capacity development. Besides a few publications largely produced by the authors in this volume (e.g., Staniforth 2014; Manders and Underwood 2015), the subject has received very limited discussion in academic literature (Harpster 2008; Ichumbaki 2011). This introductory paper aims to set the scene and provide a context for the more detailed examples and theoretical approaches explored in the papers that follow, largely focused on capacity building in the Global South, here defined as the global regions of Africa, Latin America, Asia and Oceania experiencing significant socio-economic and political challenges. More specifically, the focus of many of the papers is on the countries in the eastern Mediterranean where Honor Frost conducted research.

Essentially, this paper aims to explore the nature of capacity development in relation to maritime cultural heritage. It aims to lay the foundations and establish a benchmark for subsequent scholarship both within this volume and hopefully future research. It will provide the context for capacity building more broadly and specifically in the context of maritime archaeology, and explore, by example, regional capacity building initiatives and the theories of change that underpinned these initiatives. It will address why capacity development is necessary and the variety of challenges that are faced and how they might be tackled. It will highlight individual or institutional motivations behind these developments and how recipient governments and academic institutions engage with such activities. It will also address the funding of these activities and the effectiveness of current models for capacity building. What different methods, projects and training schemes are adopted depend on the nature and variety of the target audience and the overarching objectives. Finally, it will begin to explore how do capacity builders perceive their role and how the end users perceive the initiatives.

\section{Defining Capacity Development}

But what exactly do we mean when we use the term Capacity Development? It was first used widely in development literature from the 1980s onwards (Tadele and Bernard Manyena 2009). The United Nations Office for Disaster Risk Reduction (UNISDR) defined it as the "process by which people, organizations and society systematically stimulate and develop their capability over time to achieve social and economic goals, including through improvement of knowledge, skills, systems, and institutions-within a wider social and 
cultural enabling environment" (UNISDR 2009). The United Nations Centre for Public Administration (UNCEPA 2006) posited that capacity building on an individual level requires the development of conditions that allow individual participants to build and enhance knowledge and skills (Yamoah and Maiyo 2013). It also calls for the establishment of conditions that will allow individuals to engage in the process of learning and adapting to change (Harrison et al. 2015). The World Customs Organisation (WCO) has described capacity building as the "activities which strengthen the knowledge, abilities, skills and behaviour of individuals and improve institutional structures and processes such that the organization can efficiently meet its mission and goals in a sustainable way" (UNDP 2008).

Smith (2002) has argued that capacity building is crucial within ocean and coastal management, and that while the most pressing needs exist across the Global South, it is more appropriate to view the issue in a global context. UNESCO have approached this in similar terms and have identified capacity deficits as one of their major concerns. In the articles of the 2001 Convention on the Protection of the Underwater Cultural Heritage, the building of capacity and the establishment of research methodologies in States have been highlighted as priority areas (Dromgoole 2003). The relatively recent development of the subject, coupled with the technological reliance of its associated methodologies, means that required levels of expertise are limited to a small number of States and experts. These combined approaches are indicative of the types of approaches to capacity building that have been adopted. They are useful in partially framing how we might apply these principles to understanding the needs and gaps in relation to maritime archaeology and underwater cultural heritage. Ultimately, a useful approach is to consider the development of knowledge, ability and skills as central to our approach, and to eventually develop expertise that will provide for a greater understanding of the requirement to manage and protect our maritime cultural heritage in an informed and sustainable manner.

\section{Challenges and Threats}

When considering these objectives it is important to remember there are many diverse challenges that present threats to the maritime cultural heritage, and many hurdles to how we respond to these threats. Threats can be broadly characterised under two primary headings, natural processes of change and anthropogenic change. While marine environments are, by their very nature, dynamic and subject to continual change, contemporary climate change has significantly accelerated the rate and level of threat. Particularly, sea-level rise and an increase in the frequency and intensity of storm activity poses increased risk of inundation and coastal erosion (Erlandson 2012). A number of these regions are also particularly susceptible to seismic activity that continually impacts upon and reshapes the coast. In parallel the coastal zone across the eastern Mediterranean region is undergoing a phase of hyperdevelopment associated with large scale expansion of port and coastal infrastructure, coupled with significant demographic movement towards the region's littoral. An associated intensification of marine exploration and industrial activity poses particular pressures on the submerged cultural resource.

Against the background to these pressures a series of stakeholders have emerged that are working towards the protection and management of the maritime cultural heritage. These stakeholders come from a variety of contexts and are driven by complex and varied agendas. Are academics and pursuit of knowledge driving the agenda? Does UNESCO play a critical role in protecting the underwater cultural heritage? Are regional governments 
interested in developing a management strategy and establishing an Integrated Coastal Zone Management Plan (ICZMP), or are they simply unaware of the importance of the resource [at best!]? Have charities such as the Honor Frost Foundation determined that they want to make a change, or international governments set agendas to challenge sustainable development goals, etc.? Equally there needs to be a consideration as to the scale of the challenge-are we trying to deliver capacity on a regional, national or international level? Whom is the target recipient in terms of instilling knowledge and skills: state institutions, developers, the community, archaeologists and museum curators, or perhaps divers-all these groups of stakeholders hold a variety of vested interests and need to be skilled to different degrees and via different approaches. So, essentially, we need also to think about whom we are trying to educate and why.

Within all this complexity, heritage and capacity building is a low priority area within the broader development arena. While pressing issues of poverty, food security and climate change rightly take priority, longer term sustainable development needs to take a more robust and inclusive approach towards the environment and cultural assets. There is a strong sense of urgency around this as in an increasingly globalised society, the commodification of underwater cultural heritage poses significant issues for this non-renewable and increasingly fragile resource.

\section{A Framework Deficit}

The broader challenges of actually delivering capacity development will be addressed below, but it is worth initially considering the context of capacity development more broadly and the context of maritime cultural heritage more specifically. While awareness around the resource has been developing for decades, and the professional field of maritime archaeology has become embedded within university practice, there remains little understanding of the mechanisms to build the subject from a capacity perspective across the Global South (Khalil 2008). The specific problem has centred on the fact that maritime archaeology has been, for the most part, a subject that has developed and matured within a western context. Models around best practice tend to be focused on a well-funded and wellstructured systems of environmental governance. Previous initiatives that have attempted to import these models to the South have then often failed as they have been overly idealistic or too ambitious, based on a short-termist outlook with Westernist hierarchical and often subjugatory models of deliverance, that pay limited attention to long term sustainable goals (see Munjeri 2004; Samuels 2009). Mechanisms of evaluation or time for reflection are rarely factored into these initiatives that might provide some quantifiable measure of success. Similarly, there have rarely been forums or space for reflection or learning from the project experience, before the individual or group leading the initiative moves on to the next phase or area of research development. Many of these projects have then fallen into the process of what the anthropologist Arjun Appadurai has termed reinventing the ever same (Appadurai 1990; Morley 1998). 


\section{Practice}

As noted, capacity can be developed on a variety of levels from local, regional, national and international, that operate on individual, societal, organisational, and institutional levels (Barker 2005; UNDP 2008, 2009; Fukuda-Parr et al. 2002). Approaches can be extremely varied, ranging from training and education across a variety of levels including local antiquities employees, students and academics, and developers and divers, to establishing a record of the resource through identification and documentation, through sustainable tourism, and working with communities to determine an idea of local perspectives of maritime cultural heritage (Kusimba 2017; Weiler and Ham 2002). Funders and funding are obviously critical to developing capacity and the motives that drive funding are very varied. Governmental intervention rarely delivers capacity initiatives directly, invariably commissioning third parties or working in collaboration with capacity providers (see example of MASO below). However, government, often but not exclusively, identifies the need, also highlighted by NGOs, charitable foundations, the academic and /or international community (e.g. UNESCO, UN) etc., who to varying degrees, are proactive in determining the nature and objectives of the capacity being developed.

\section{Barriers to Capacity Development}

We can identify a set of root causes underlying the weak development of maritime archaeology as a research area, and as a significant cultural or environmental resource that is poorly protected and understood. At a structural level there are significant deficits in terms of government or institutional support, associated with chronic underfunding and the general marginalistaion of heritage and environment within development activity. A key aspect of this is the level of awareness associated with the resource across the Global South. Core issues surrounding the visibility of the resource, and the complexities surrounding its accessibility underpin many of its associated development challenges (Lane 2012). While the broader terrestrial archaeological resource has attained a higher public profile, the maritime resource remains poorly understood and poorly recognised. As a consequence, many structural elements associated with the protection and management of the resource are missing, or poorly developed. Some of this is associated with the colonial inheritance of institutional and legislative heritage structures (Byrne 1991; Trakadas 2012). Many national and regional museums across the South were established as colonial ventures. Severe under funding have often trapped these institutions in decades old practice and interpretative frameworks that have progressed little. Few of these institutions have fully embraced the narratives, and associated resources of the sea and the role it has played in past people's lives. Similarly, much of the heritage legislative provision was formulated during the colonial period when the maritime resource was largely excluded from the range of sites and landscapes identified (see Long 2000; Parthesius 2011). Consequently, the maritime cultural resource has suffered from very weak legislative and institutional protection. This has been somewhat alleviated by the 2001 UNESCO Convention on the Protection of the Underwater Cultural Heritage, at least from an awareness perspective, as many countries across the South move towards its ratification. However, the 2001 Convention can only be but one mechanism associated with national or State level protection, and the absence of policing mechanisms associated with it will remain a primary hinderance to its successful implementation. 
We can further identify a set of obstacles at a practical level. This situation is exacerbated by the paucity of professionals working in this area. Few universities or museums offer training opportunities, leading to a significant shortage of qualified individuals able to take up posts, even if funding allowed. This lack of a knowledge base has consequences for decision making in terms of resource protection and management. Resource management is further constrained by the limited use of key tools like Environmental Impact Assessment (EIA) or Integrated Coastal Zone Management Plan (ICZMP) or the Marine Spatial Planning (MSP). Even where these instruments are available, the archaeological resource is often excluded, or dealt with in a cursory manner but unskilled operatives, or by specialists from other fields. The limited development of investigative or research frameworks further limit the ability of a State to undertake a quantification of the nature and extent of the resource. Of particular concern is the general absence of conservation knowledge. Even when submerged cultural material is identified, or even recovered, there is rarely the expertise or associated facilities to care for it.

Further issues can be identified from a subjective perspective. In general, there is a high level of inertia and disinterest at a political level when it comes to caring for the resource (Flecker 2002). There have been specific instances when certain governments have become more interested, but this has often been related to profit-driven investigation projects led by private firms. The agreements between the governments of Mozambique and Cape Verde with Arqueonautas Worldwide stand out as notable examples (see Duarte 2012). From a more theoretical perspective there are also issues in terms of perceptions of heritage. Many decision makers regard maritime archaeological projects as essentially westernist practice, on shipwrecks that are primarily associated with colonialism. The continuing dominance of western-led projects at these sites, and the paucity of local expertise and capacity, further compounds this impression. Similarly, coastal forts or mercantile settlements are often associated with European settlements that facilitated and governed vicious industries like slavery (Harrison 2004). Value systems tend then to orientate away from these site types and places towards embedded meaning contained in local landscapes, objects and environment (Pwiti and Ndoro 1999). Intangible heritages of memory and tradition often play a far more prominent role in many of these societies (Ahmad 2006). Heritage values are often directed away from the physical architectural of past subjugation, towards heritage belief systems around place and material culture. Differing cultural contexts, and often very different approaches to practice, can lead to misunderstanding, apathy and even conflict. An integral part of capacity building is then developing robust understandings of local context and values. Initial intensive engagement with local partners to identify needs and challenges is vital. Co-production towards project development becomes an essential part of building frameworks of support and development (Jones 2017). The resource, as identified by heritage managers and practitioners, is largely the shipwreck resource. It has been viewed or perceived as the site type under most threat and has, therefore, been the focus of protection, legislation and documentation. This does not always resonate with people who perceive that the authorities have no interest in local maritime pasts and connections. European shipwrecks in Africa, for example, are often viewed as the heritage of others. Wrecks are accidental sites that form part of a culture passing by. It is difficult to show how individual shipwrecks impact on local circumstances and developments. Shipwrecks often form part of darker histories of colonial oppression, war, etc., that local stakeholders may want to downgrade or, at worst, forget. 


\section{Building Capacity to Effect Change}

We are clear that single non-transferable models of development cannot be applied to every country. Similarly, an idealised western model cannot necessarily be expected to work in South America or Sub-Saharan Africa, simply because it has proved successful within a western European or other regional context, for example. However, there are a number of key stages that the development of a successful in-country model needs to progress through. A core preliminary requirement, that will require continual updating, is the identification and quantification of the resource. Numerous approaches to the development of State inventories exist (see examples below), and their level of analysis and documentation will often be dependent on the availability of financial resources. The production of inventories will be dependent on a parallel process of professional skills development and training. This is ideally conducted within a university environment, with continuing professional development taking place within the relevant state heritage institutions or agencies. Robust programmes of site and environmental management are required to ensure resource protection within a comprehensive legislative framework that encompasses an integrated approach towards environment and resource management. These should include a policyled approach that includes instruments ranging from marine protected areas, antiquities control to individual site management strategies. As we have already noted, enforceable monitoring and policing mechanisms are also essential. The establishment of an associated collaborative research framework is further required to develop understandings of the context of the resource and better aid decision-making. Once these foundations are in place it is necessary to continue to develop informed and working networks between government, researchers, developers and other resource users to ensure there are joined-up approaches to resource development. Further strategies aimed at developing appreciations and understandings amongst coastal communities of the resource are an integral part of this process. We recognise maritime cultural heritage can play a pivotal role in strengthening community resilience through further developing a sense of place and identity, and through the formulation of sustainable development strategies centred on the resource.

While these are central deliverables in any successful maritime cultural heritage programme of national development, there is no agreed pathway on how such steps could be achieved. Given the complexity of political governance in many of these regions, central government unfortunately cannot be relied upon to deliver this framework. This can often be related to inertia within government circles, while corruption is a further factor hindering development in a number of countries. Traditionally environment and culture has played a minor, or peripheral, role in International Development, but this is changing. Capacity for environmental management and heritage protection is becoming increasingly common in the area of bilateral aid, with the Scandinavian countries being supportive of cultural projects and initiatives. The UK government is increasingly directing financial support towards culture and heritage, with the recent development of the Cultural Protection Fund (CPF) (www.britishcouncil.org/arts/culture-development/cultural-protection -fund), various funding streams under Newton, and the inclusion of a heritage stream under the Global Challenges Research Fund (GCRF) (www.ukri.org/research/global-challenges -research-fund/), administered by RCUK, being noteworthy. Of particular interest under these models was the effective devolution of project development and deliverance away from government agencies to university researchers under these schemes.

These initiatives are still ultimately accountable to the government where the funding originated from, and the degree of flexibility, and responsiveness, the researchers have is 
highly variable. They are also clear examples of soft diplomacy, soft power, which are an intrinsic part of broader government agendas. Given these potential conflicts, there is a strong argument that the non-governmental agencies have a stronger role to play within these arenas. The role of the Honor Frost Foundation, for example, is proving critical to the development and expansion of the subject in the eastern Mediterranean, in a manner that is far more ambitious and flexible than government-controlled development practice. Other foundations like ARCADIA (www.arcadiafund.org.uk), will increasingly play a role as well, as philanthropic funding continues to become a central feature of the funding environment. The role of commercial bodies is less clear, with significant problems existing in terms of the for-profit treasure hunting companies that exist. Potential conflicts of interest can also emerge in terms of conservation funding sourced from international exploration companies.

\section{Case Studies}

A number of notable examples associated with capacity development have taken place across the South. An initiative to support project work and establish a dedicated research centre in Sri Lanka supported by the Netherlands, is of particular interest as it provides one of the earliest examples of the establishment of such a resource (Parthesius et al. 2005). Unfortunately, the centre was extensively damaged during the 2004 tsunami which greatly hindered the project's further development. A significant set of projects surrounding maritime and underwater cultural heritage were subsequently conducted in South Africa and Tanzania (Ichumbaki 2011; Jeffery and Parthesius 2013; Sharfman 2017), succeeded by a series of successful training and development initiatives in this field in South Africa (Boshoff 1998; Gribble 2002; Sharfman et al. 2012). In 2009, the EU under its Tempus III programme, established the Alexandria Centre for Maritime Archaeology and Underwater Cultural Heritage (CMAUCH). The project aimed to create a specialised center for postgraduate studies, and was set up in partnership with the University of Southampton, the Centre d'Etudes Alexandrines, Egypt, the Nautical Archaeology Society, UK, and Ulster University, Northern Ireland. Ten years later the CMAUCH continues to provide education and training in aspects of maritime and underwater archaeology predominantly at Diploma and Masters levels (Khalil 2008). The development of the CMAUCH and the workshop that was held at its launch (the '2010 International Workshop on Underwater Cultural Heritage'), was partly responsible for the formation in 2010 of the Maritime Archaeological Stewardship Trust (MAST) by one of the authors of this paper, Lucy Blue. MAST aimed to promote, protect and build capacity in relation to the maritime cultural heritage of the Arabian Gulf. MAST subsequently went on to be involved in a number of capacity building initiatives in the region, including a collaborative project known as the Maritime Archaeological Survey of Oman (MASO) that was commissioned in 2014 as a joint initiative between the Oman Ministry of Heritage and Culture, MAST, and the Western Australian Maritime Museum's Department of Maritime Archaeology. The aim of MASO was to "further extend capacity to identify and manage the maritime archaeological resource of Oman" and "to develop a comprehensive holistic approach to maritime heritage management" (Blue et al. forthcoming). Further collaborative maritime heritage initiatives were undertaken by MAST with Abu Dhabi Tourism and Cultural Authority (Blue et al. 2013), together with lectures, workshops with stakeholders, and small-scale research projects (Blue et al. 2014) all of which were designed to build capacity for maritime cultural 
heritage in the region. In South America a series of important initiatives have taken place in Argentina (Elkin and Cafferata 2001; also see Underwood and Manders in this volume), while Flinders University in Australia have led a series of important interventions across Southeast Asia (see Staniforth and O'Toole in this volume). More recently, the Rising from the Depths network (risingfromthedepths.com) aims to identify how the tangible submerged and coastal Marine Cultural Heritage (MCH), and its associated intangible aspects, can stimulate ethical, inclusive and sustainable economic growth across East Africa.

\section{How Effective are Current Models?}

Whilst an in-depth assessment of the value and effectiveness of capacity development efforts should be addressed, this is actually quite difficult to qualify. The reality is that not many of capacity development programmes evaluate their impact or have any scope for reflection or evaluation. A number of the papers presented in this special issue begin to readdress this lacuna by presenting models to assess the impact of implementation. But historically many capacity building programmes embark on a journey that clearly identifies a challenge but often leaves limited scope for evaluating the impact of the approach or identify whether or not indeed the approach was successful over a short, medium or longer term. How successful and importantly sustainable, the impact of the capacity developed is over time, is often overlooked, and only limited projects plan for a review period after the project comes to an end (e.g. ICCROM, Sharja). Thus, the long term effectiveness of projects is frequently not possible to determine and whether or not the challenges have been fully overcome, is not known. Equally, as there is limited evaluation, another factor is not necessarily taken into account in terms of effectiveness and sustainability, that is how effective the recipient individual, institution, or community believe the project was. How much involvement does this sector have in determining the nature of the capacity in the first place? Does the recipient perceive the role of the capacity provider, whether that be funder or deliverer, to be appropriate to the identified need? Thus, the sustainability of these programmes still remains in question until review and assessment is instigated. One factor however, that does make a lasting difference to the sustainable nature of capacity building initiatives, are people. To ensure long term capacity is developed and permanently instilled ensuring a sustainable platform, it is critical to build local stewardship and work with the right individuals, appropriately qualified, driven and determined to ensure successful and sustainable capacity development. Core challenges remain around identifying sustainable funding mechanisms that are not driven by short-term targets, but also in the identification of the individuals who will engage with these programmes and develop legacy outcomes.

\section{Special Issue Papers}

The following set of papers in this special issue examine aspects of capacity development within maritime archaeology from a number of personal and geographical perspectives. The approach is not to argue for, or promote, a favoured perspective or model, but to rather present an overview of aspects of contemporary practice, with a view to encouraging further dialogue and engagement with this area of concern. As the subject continues to 
develop across the Global South more informed engagement with some of the key themes and challenges presented here will be important. Training and skills development has always been a core concern of maritime archaeologists and Chris Underwood and Martijn Manders present an overview of international capacity building training programmes, and look at some of the components that lead to the success, or otherwise of these programmes and the contribution they make to increasing professional heritage management capacity. Mark Staniforth has been at the forefront of the continuing development of maritime archaeology in Australia and Southeast Asia for many years. Here, both he and his colleague Paddy O'Toole, present an overview of an innovative case study project from Vietnam. Stella Demesticha from Cyprus and Lucy Semaan from Lebanon, as well as Ziad Morsy as a representative of the Centre for Maritime Archaeology and Underwater Cultural Heritage in Alexandria, Egypt, have been heavily involved with the Honor Frost Foundation and are leading a number of its initiatives in their respective countries. Here they provide an overview of the challenges that underpin the development of maritime archaeology across the eastern Mediterranean, and how a variety of initiatives including the input of the Honor Frost Foundation, have helped developed capacity over time. The final two papers take a more theoretical approach to the subject with Robert MacKintosh structuring a framework for analysis that borrows a theoretical concept of capacity from the environmental sciences and demonstrates how it can be applied to maritime archaeology through the examination of a number of case studies, while Kate Recinos and Lucy Blue presents a model that outlines parameters for capacity development in relation to maritime archaeology. Both of these later approaches largely arose from doctoral and masters research. Collectively the editors believe this special issue provides an insightful over view of current capacity initiatives with respect to maritime cultural heritage, some reflection on the context in which capacity is developed and delivered, and some new approaches as to how capacity building can be more effectively delivered and assessed in the future.

Acknowledgements The authors would like to thank the Honor Frost Foundation, for funding the original session that this collection of papers is based on, from IKUWA VI, 2016. They would also like to thank all of the authors for their contributions to this special issue. Particular thanks are due to Athena Trakadas, who supported and guided this publication.

Open Access This article is distributed under the terms of the Creative Commons Attribution 4.0 International License (http://creativecommons.org/licenses/by/4.0/), which permits unrestricted use, distribution, and reproduction in any medium, provided you give appropriate credit to the original author(s) and the source, provide a link to the Creative Commons license, and indicate if changes were made.

\section{References}

Ahmad Y (2006) The scope and definitions of heritage: from tangible to intangible. Int J Herit Stud 12(3):292-300

Appadurai A (1990) Disjuncture and difference in the global economy. Theory Cult Soc 7(2):295-310

Barker A (2005) Capacity building for sustainability: towards community development in coastal Scotland'. J Environ Manag 75(1):11-19

Blue L, Vosmer T, Green J (forthcoming) The maritime archaeological survey of Oman. In: Rodrigues J, Traviglia A (eds) Shared heritage: proceedings from the sixth international congress for underwater archaeology (IKUWA6), Western Australian Museum, Fremantle. Archaeo Press, Oxford, 28 November to 2 December 2016

Blue L, Strutt K, Sheehan P, Jackson P, Beech M (2013) Developing an integrated policy for the maritime and coastal heritage of the UAE: a collaborative approach. Proc Semin Arab Stud 43:63-76 
Blue L, Al-Jahwari NS, Staples E, Giorgio L, Croce P, Ghidoni A, Al Busaidi A, Belfioretti L (2014) Maritime footprints: examining the maritime cultural landscape of Masirah Island, Oman, past and present. Proc Semin Arab Stud 44:53-68

Boshoff JJ (1998) NAS courses in South Africa. Bull Aust Inst Marit Archaeol 22:133

Byrne D (1991) Western hegemony in archaeological heritage management. Hist Anthropol 5(2):269-276

Dromgoole S (2003) 2001 UNESCO convention on the protection of the underwater cultural heritage. Int J Mar Coast Law 18(1):59-108

Duarte RT (2012) Maritime history in Mozambique and East Africa: the urgent need for the proper study and preservation of endangered underwater cultural heritage. J Marit Archaeol 7(1):63-86

Elkin D, Cafferata H (2001) Underwater archaeology and cultural tourism-a mutual benefit proposal for Patagonia. J Australas Inst Marit Archaeol 25:83

Erlandson JM (2012) As the world warms: rising seas, coastal archaeology, and the erosion of maritime history. J Coast Conserv 16(2):137-142

Flecker M (2002) The ethics, politics, and realities of maritime archaeology in Southeast Asia. Int J Naut Archaeol 31(1):12-24

Fukuda-Parr S, Lopes C, Malik K (2002) Capacity for development: new solutions to old problems. United Nations Development Programme, New York

Gribble J (2002) Past, present, and future of maritime archaeology in South Africa. International Handbook of Underwater Archaeology. Springer, Boston, pp 553-567

Harpster M (2008) Maritime archaeology and maritime heritage protection in the disputed territory of Northern Cyprus. J Marit Archaeol 3(1):3-13

Harrison D (2004) Introduction: contested narratives in the domain of world heritage. Curr Issues Tour 7(4-5):281-290

Harrison QU, Eni DD, Harrison UE, Ukata SU, Akintoye OA (2015) National capacity building strategy for sustainable development through environmental management education in Nigeria. J Emerg Trends Econ Manag Sci 6(7):324-331

Ichumbaki E.B. (2011) Tanzania's maritime and underwater cultural heritage assets: strategies towards sustainable conservation and management. In: Proceedings of the Asia-Pacific regional conference on underwater cultural heritage, pp 553-564. https://pdfs.semanticscholar.org/ce44/ef6ba537e448a2b 7610627915e8411779a60.pdf. Accessed 9, 2019

Jeffery B, Parthesius R (2013) Maritime and underwater cultural heritage initiatives in Tanzania and Mozambique. J Marit Archaeol 8(1):153-178

Jones S (2017) Wrestling with the social value of heritage: problems, dilemmas and opportunities. J Commun Archaeol Herit 4(1):21-37

Khalil E (2008) Education in maritime archaeology: the Egyptian case study. J Marit Archaeol 3(2):85-91

Kusimba CM (2017) Community archaeology and heritage in coastal and western Kenya. J Commun Archaeol Herit 4(3):218-228

Lane P (2012) Maritime and shipwreck archaeology in the western Indian Ocean and southern Red Sea: an overview of past and current research. J Marit Archaeol 7(1):9-41

Long DL (2000) Cultural heritage management in post-colonial polities: not the heritage of the other. Int J Herit Stud 6(4):317-322

Manders MR, Underwood CJ (2015) UNESCO field school on underwater cultural heritage 2009-2011, Thailand capacity building in the Asian and Pacific region. In: Tripathi S (ed) Shipwrecks around the world: revelations of the past. Delta Book World, New Delhi, pp 730-748

Morley D (1998) So-called cultural studies: dead ends and reinvented wheels. Cult Stud 12(4):476-497

Munjeri D. (2004) Anchoring African cultural and natural heritage: the significance of local community awareness in the context of capacity-building. Linking Universal and Local Values, UNESCO World Heritage Papers, Paris, pp 75-80

Parthesius R (2011) Shared Heritage? Shared Responsibility: reflections on the role of 'shared' colonial heritage within capacity building programmes in the post-colonial world. In: Proceedings of the inaugural Asia-Pacific regional conference on underwater cultural heritage. Asian Academy for Heritage Management, Manila, pp 641-651.

Parthesius R, Millar K, Jeffery B (2005) Preliminary report on the excavation of the 17th-century AngloDutch East-Indiaman Avondster in Bay of Galle, Sri Lanka. Int J Naut Archaeol 34(2):216-237

Pwiti G, Ndoro W (1999) The legacy of colonialism: perceptions of the cultural heritage in Southern Africa, with special reference to Zimbabwe. Afr Archaeol Rev 16(3):143-153

Samuels KL (2009) Trajectories of development: International heritage management of archaeology in the Middle East and North Africa. Archaeologies 5(1):68-91

Sharfman J (2017) Troubled waters: developing a new approach to maritime and underwater cultural heritage management in Sub-Saharan Africa. Leiden University Press, Leiden 
Sharfman J, Boshoff J, Parthesius R (2012) Maritime and underwater cultural heritage in South Africa: the development of relevant management strategies in the historical maritime context of the southern tip of Africa. J Marit Archaeol 7(1):87-109

Smith HD (2002) The role of the social sciences in capacity building in ocean and coastal management. Ocean Coast Manag 45(9-10):573-582

Staniforth M (2014) Raising awareness about underwater cultural heritage in Vietnam. In: Proceedings of the 18th ICOMOS general assembly and scientific symposium, ICOMOS, Venice, Italy, pp 446-451.

Tadele F, Bernard Manyena S (2009) Building disaster resilience through capacity building in Ethiopia. Disaster Prev Manag Int J 18(3):317-326

Trakadas A (2012) Navigating the al-bahr al-Muzlîm: an assessment of the investigation, mitigation and preservation of Morocco's maritime cultural heritage. J Marit Archaeol 7(1):165-192

United Nations Committee of Experts on Public Administration (UNCEPA) (2006) Definition of basic concepts and terminologies in governance and public administration. United Nations Economic and Social Council, Geneva, Switzerland

United Nations Development Programme (2008) Capacity development practice note. United Nations Development Programme, New York

United Nations Development Programme (2009) Capacity development: a UNDP primer. United Nations Development Programme, New York

United Nations Office for Disaster Risk Reduction (UNISDR) (2009) UNISDR terminology for disaster risk reduction, Switzerland, Geneva

Weiler B, Ham SH (2002) Tour guide training: A model for sustainable capacity building in developing countries. J Sustain Tour 10(1):52-69

Yamoah EE, Maiyo P (2013) Capacity building and employee performance. Can Soc Sci 9(3):42

Publisher's Note Springer Nature remains neutral with regard to jurisdictional claims in published maps and institutional affiliations. 